\title{
Subcritical water extraction of amino acids from Atacama Desert soils
}

\author{
Xenia Amashukeli, ${ }^{1}$ Christine C. Pelletier, ${ }^{1}$ James P. Kirby, ${ }^{1}$ and Frank J. Grunthaner ${ }^{1}$ \\ Received 14 September 2006; revised 28 March 2007; accepted 8 May 2007; published 7 September 2007.
}

[1] Amino acids are considered organic molecular indicators in the search for extant and extinct life in the Solar System. Extraction of these molecules from a particulate solid matrix, such as Martian regolith, will be critical to their in situ detection and analysis. The goals of this study were to optimize a laboratory amino acid extraction protocol by quantitatively measuring the yields of extracted amino acids as a function of liquid water temperature and sample extraction time and to compare the results to the standard $\mathrm{HCl}$ vapor-phase hydrolysis yields for the same soil samples. Soil samples from the Yungay region of the Atacama Desert (Martian regolith analog) were collected during a field study in the summer of 2005. The amino acids (alanine, aspartic acid, glutamic acid, glycine, serine, and valine) chosen for analysis were present in the samples at concentrations of 1-70 parts-per-billion. Subcritical water extraction efficiency was examined over the temperature range of $30-325^{\circ} \mathrm{C}$, at pressures of 17.2 or $20.0 \mathrm{MPa}$, and for water-sample contact equilibration times of $0-30 \mathrm{~min}$. None of the amino acids were extracted in detectable amounts at $30{ }^{\circ} \mathrm{C}$ (at 17.2 MPa), suggesting that amino acids are too strongly bound by the soil matrix to be extracted at such a low temperature. Between $150^{\circ} \mathrm{C}$ and $250^{\circ} \mathrm{C}$ (at $17.2 \mathrm{MPa}$ ), the extraction efficiencies of glycine, alanine, and valine were observed to increase with increasing water temperature, consistent with higher solubility at higher temperatures, perhaps due to the decreasing dielectric constant of water. Amino acids were not detected in extracts collected at $325^{\circ} \mathrm{C}$ (at $20.0 \mathrm{MPa}$ ), probably due to amino acid decomposition at this temperature. The optimal subcritical water extraction conditions for these amino acids from Atacama Desert soils were achieved at $200{ }^{\circ} \mathrm{C}, 17.2 \mathrm{MPa}$, and a water-sample contact equilibration time of $10 \mathrm{~min}$.

Citation: Amashukeli, X., C. C. Pelletier, J. P. Kirby, and F. J. Grunthaner (2007), Subcritical water extraction of amino acids from Atacama Desert soils, J. Geophys. Res., 112, G04S16, doi:10.1029/2006JG000308.

\section{Introduction}

[2] Amino acids are considered to be one of the primary target organic biomarkers indicative of extant and extinct life in the Solar System. The chemical and physical properties of these molecules are well studied. Unique subsets of amino acids are found in biology, and amino acid chirality enables differentiation between their biotic and abiotic formation mechanisms. Amino acids have been successfully synthesized from a mixture of methane, ammonia, and water in the presence of electric discharges in abiotic chemistry experiments [Miller, 1953]. More than 70 amino acids were found in the Murchison meteorite [Cronin et al., 1988]. Although more generally attributed to remnants of terrestrial contamination, the L-enantiomeric excess of amino acids in Murchison meteorite has also been suggested to result from an extraterrestrial process of asymmetric synthesis [Pizarello and Cronin, 2000].

[3] Extrapolating from Viking experiments [e.g., Biemann et al., 1976; Biemann, 1979; Biemann and Lavoie, 1979; Oyama et al., 1976, 1977; Levin and Straat, 1977a, 1977b],

\footnotetext{
${ }^{1}$ Jet Propulsion Laboratory, Pasadena, California, USA.
}

Copyright 2007 by the American Geophysical Union. 0148-0227/07/2006JG000308\$09.00 any amino acids expected to be found by instrumental in situ analytical studies of the Martian regolith should be present in trace quantities. Desert soils, because of their aridity, are some of the most obvious candidates for the Martian soil analogs that would contain trace amounts of amino acids. In particular, the Atacama Desert of Chile provides one of the best Mars analogs on Earth [Cameron and Blank, 1965]. The sulfate-rich soils of the sparsely populated Atacama arid plateau regions are similar to the regolith observed on Mars [Squyres et al., 2004]. Summer precipitation near the mountains of the Atacama is rare, and the desert plateau can remain dry for many years, making this region one of the driest places in the world [McKay et $a l ., 2003]$. The current dry conditions have persisted there for nearly 15 Myr [Ericksen, 1983a, 1983b]. Although many areas in the Atacama receive a marine fog that supports life in the form of lichens and hypolithic algae, the Yungay region of Atacama is blocked by a coastal mountain range, making it nearly impossible for the marine fog to penetrate and support any life in that region. Low levels of culturable bacteria and the presence of oxidized organics [Navarro-Gonzales et al., 2003] suggest that this environment is highly oxidizing and, from this perspective, is similar to Mars [Klein, 1978, 1979]. Although there are substantial differences between the Yungay soils and the 


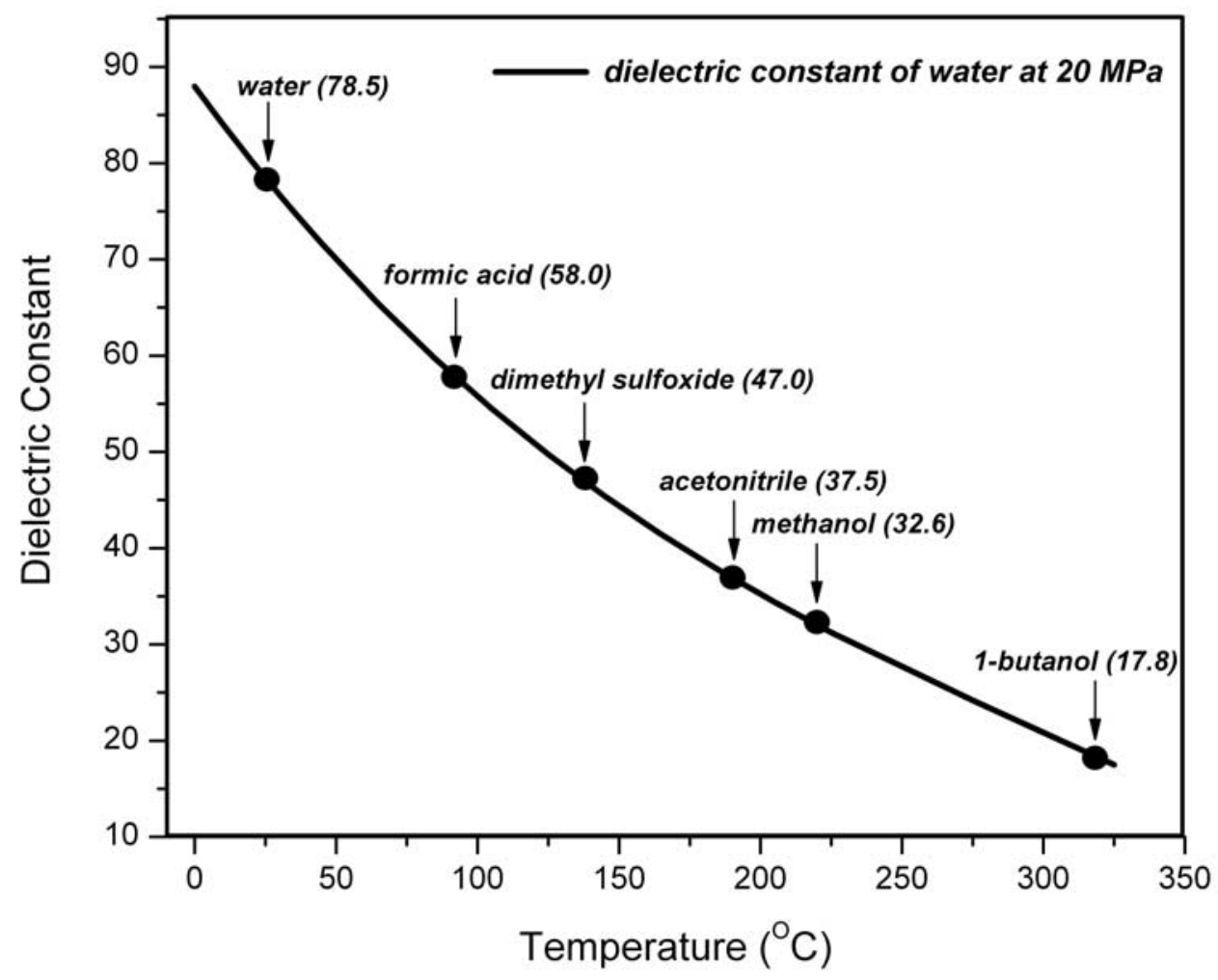

Figure 1. The dielectric constant of water is plotted as a function of temperature at constant pressure $(20 \mathrm{MPa})$. As the temperature increases, the dielectric constant decreases. Superimposed with the plot are the dielectric constants (solid circles) of several organic solvents; the dielectric constant values of these solvents (including water) at $25{ }^{\circ} \mathrm{C}$ and $0.1 \mathrm{MPa}$ are given in parentheses. At high temperatures and pressure, subcritical water is similar to organic solvents in its ability to dissolve relatively nonpolar organic compounds.

Mars regolith, such as their chemical composition and ambient temperature profiles, the photochemical reaction processes responsible for the formation of oxidizing compounds might be similar [Quinn et al., 2005]. These characteristics make the Yungay region of the Atacama Desert an ideal field-testing ground for in situ Mars analytical instrumentation developed for the detection of trace amounts of amino acids.

[4] In the past several years, a series of field experiments addressing the organic composition and oxidation chemistry of soils have been conducted in the Atacama Desert [e.g., Navarro-Gonzales et al., 2003; Skelley et al., 2005; Quinn et al., 2005; Lester et al., 2007; Skelley et al., 2007]. Partsper-billion concentration levels of amino acids were detected by the Mars Organic Analyzer (MOA) equipped with a microfluidic capillary electrophoresis chip [Skelley et al., 2005]. In the summer of 2005, a series of samples analyzed in the field as well as in the laboratory - were collected from an area in the Yungay region designated Yungay 1122 hill [Skelley et al., 2007].

[5] If trace amounts of proteinaceous amino acids are present in the Martian regolith and Mars-analog Atacama soils, then the means by which these molecules are extracted from the particulate solid matrix is critical to the successful implementation of in situ detection and analysis experiments. To address this issue, we have developed a subcritical water extraction (SCWE) system [Amashukeli et al., 2006] designed to recover trace organic compounds with minimal degradation and decomposition. The operational principle of the SCWE is based on the unique property of liquid water in which its dielectric constant changes as a function of temperature and pressure [Fernandez et al., 1997]. At $30^{\circ} \mathrm{C}$ and $0.1 \mathrm{MPa}$, the dielectric constant of water is 79.6 due to the strong dipole-dipole electrostatic interactions between individual molecular dipoles. At higher water temperatures, the consequential thermal energy excess causes disorientation of molecular dipoles, yielding smaller dielectric constants. For instance, subcritical water at $325{ }^{\circ} \mathrm{C}$ and $20 \mathrm{MPa}$ has a dielectric constant of 17.5 , which is similar to the dielectric constants of relatively nonpolar organic solvents, such as acetone and 1-butanol [Wolfarth, 1991]. The dielectric constant of supercritical water at $575{ }^{\circ} \mathrm{C}$ and $50 \mathrm{MPa}$ is 2.27 , which is the same as the dielectric constant of benzene [Wolfarth, 1991]. The relationship between dielectric constants for several common organic solvents and water are illustrated in Figure 1. As the dielectric constant of water is lowered, the solubility of nonpolar molecules is enhanced, while ions and polar molecules become less soluble. Currently, subcritical and supercritical water technologies are used to extract a wide range of organic compounds from various solid matrixes for analysis [e.g., Hartonen et al., 1997; Ibanez et al., 2003; Ong et al., 2006] and for environmental remediation [e.g., Lagadec et al., 2000; Hawthorne et al., 2000]. The advan- 


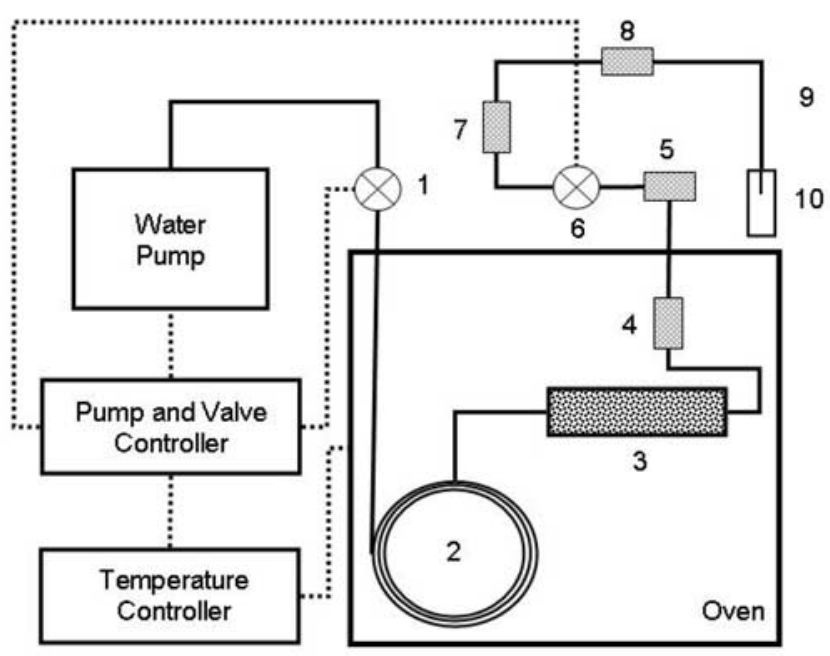

Figure 2. Laboratory SCWE instrument. The electrical connections are represented by dashed lines, while the path of subcritical water is shown by solid lines. In a typical extraction, the high-pressure water passes through a supply valve (1) into a preheating coil (2) (2-m, 0.75-mm ID) and into a sample cell (3). To prevent soil from contaminating the instrument, $2-\mu \mathrm{m}(4)$ and $0.5-\mu \mathrm{m}$ (5) filters are placed before an eluent valve (6). Another series of $2-\mu \mathrm{m}$ filters (7) and (8) are positioned before the flow restrictor (9). The amino acid extracts are collected in a crimp-top vial (10).

tage of the SCWE over other more traditional laboratory extraction methods (e.g., soxhlet extraction, supercritical $\mathrm{CO}_{2}$ extraction) is its unique ability to extract a broad spectrum of organic compounds with dissimilar physical and chemical properties (e.g., polarity, volatility, charge, and size) by tuning the dielectric constant of high-purity liquid water. In this work, we show that in addition to using this single solvent system, the SCWE instrument is able to rapidly $(\sim 10 \mathrm{~min})$ extract detectable amounts of amino acids from trace bioload soil samples.

[6] In this report, we examine the effect of temperature on extraction efficiency and the effect of the time of contact between nonflowing subcritical water and the sample ("equilibration time"). Since amino acids are susceptible to decomposition in hot water [White, 1984; Bernhardt et al., 1984; Miller and Bada, 1988], our subcritical water extraction protocols focused on the $\mathrm{T}=30{ }^{\circ} \mathrm{C}-250{ }^{\circ} \mathrm{C}$ range to minimize decomposition while allowing for efficient extraction of amino acids. Prolonged high-temperature exposure of amino acids in liquid water might also lead to racemization. Skelley et al. [2007] demonstrated that racemization of amino acids extracted from these Atacama Desert soils under subcritical extraction conditions yielded $\mathrm{D} / \mathrm{L}$ ratios $(\sim 0.4)$ that indicated biogenic amino acid content that was not racemic. This suggests that these SCWE extraction conditions did not have a significant effect on the observed enantiomeric ratios. Currently, we are conducting a systematic study of the amino acid racemization rates under subcritical water extraction conditions, which will be published elsewhere.

[7] Here we present experimental results on optimizing SCWE performance using two different extraction proto- cols. Quantitative amino acid analysis of extracts was carried out using high-performance liquid chromatography (HPLC) with fluorescence detection. The SCWE extracted amounts of the amino acids were compared to those measured using a standard $\mathrm{HCl}$ amino acid hydrolysis procedure, which recovers nearly $100 \%$ of amino acids from solids [e.g., Tsugita et al., 1987; Keil and Kirchman, 1991]. Our extraction efficiencies are discussed in terms of peptide hydrolysis reactions, decomposition processes, and the solubility of free amino acids in subcritical water. As the result of this work, we are able to present an optimized SCWE protocol for detection and analysis of amino acids in Mars-analog Atacama samples, which will be ultimately used in the implementation of the primary extraction component of the integrated in situ Urey instrument suite [Bada et al., 2005].

\section{Methods and Materials}

\subsection{SCWE Instrument}

[8] Experiments were performed with a laboratory SCWE instrument (Figure 2), similar to the experimental set-up reported previously by Hawthorne et al. [1994]. The instrument consists of a 260D syringe pump and a controller (ISCO Inc., Lincoln, Nebraska), a Varian 1100 GC oven (Varian, Inc., Palo Alto, California), motor-driven valves (ISCO Inc., Lincoln, Nebraska), a pxz4 micro-temperature controller (Fuji Electric, Tokyo, Japan), and a capillary flow restrictor (ISCO Inc., Lincoln, Nebraska). Soil samples $(1.0 \mathrm{~g})$ were loaded into a sample cell, which consisted of stainless steel tubing $( \pm 0.49 \mathrm{~cm} \mathrm{ID,} 0.64 \mathrm{~cm} \mathrm{OD}$, and $5.0 \mathrm{~cm}$ length) with analytical column end fittings equipped with 2.0- $\mu \mathrm{m}$ transmission frits (Valco Instruments Inc., Houston, Texas). The sealed sample cells were assembled inside the oven and tested for water leaks before each extraction at 17.2 $\mathrm{MPa}$ and $30{ }^{\circ} \mathrm{C}$. The maximum leak rate during the extractions was less than $0.001 \mathrm{ml} / \mathrm{min}$. The flow rates during extractions were $0.700 \pm 0.200 \mathrm{ml} / \mathrm{min}$ at $30{ }^{\circ} \mathrm{C}$ and $1.650 \pm 0.500 \mathrm{ml} / \mathrm{min}$ at $325{ }^{\circ} \mathrm{C}$. The rate of the water flow through the SCWE instrument without a sample cell was $2.100 \pm 0.150 \mathrm{ml} / \mathrm{min}$.

\subsection{SCWE Extraction Protocols}

[9] Two types of subcritical water extraction protocols were performed in this study: single-point and continuous, as shown in Figure 3. In a single-point extraction protocol, amino acids were extracted from $1.0 \mathrm{~g}$ of soil at a chosen fixed temperature and equilibration time, with a fixed head pressure of 17.2 $\mathrm{MPa}$. Equilibration time is defined as the time during which nonflowing subcritical water is allowed to interact with a soil sample before flow is resumed. Each single-point extraction yielded $6.0 \mathrm{ml}$ of eluent (extract).

[10] In the continuous extraction protocol, amino acids were extracted from a single 1.0 -g aliquot of soil, where 6.0-ml eluent fractions, corresponding to different extraction temperatures, were sequentially collected at the end of 5 -min equilibration periods. A 5-min equilibration time was used for two reasons: (1) to minimize amino acid decomposition in subcritical water and (2) to optimize transmission frit performance, which would have been compromised by prolonged exposure to water at high temperature and pressure. The continuous extraction temperatures were $30{ }^{\circ} \mathrm{C}, 150{ }^{\circ} \mathrm{C}, 200{ }^{\circ} \mathrm{C}, 250{ }^{\circ} \mathrm{C}$, and $325{ }^{\circ} \mathrm{C}$. The head 


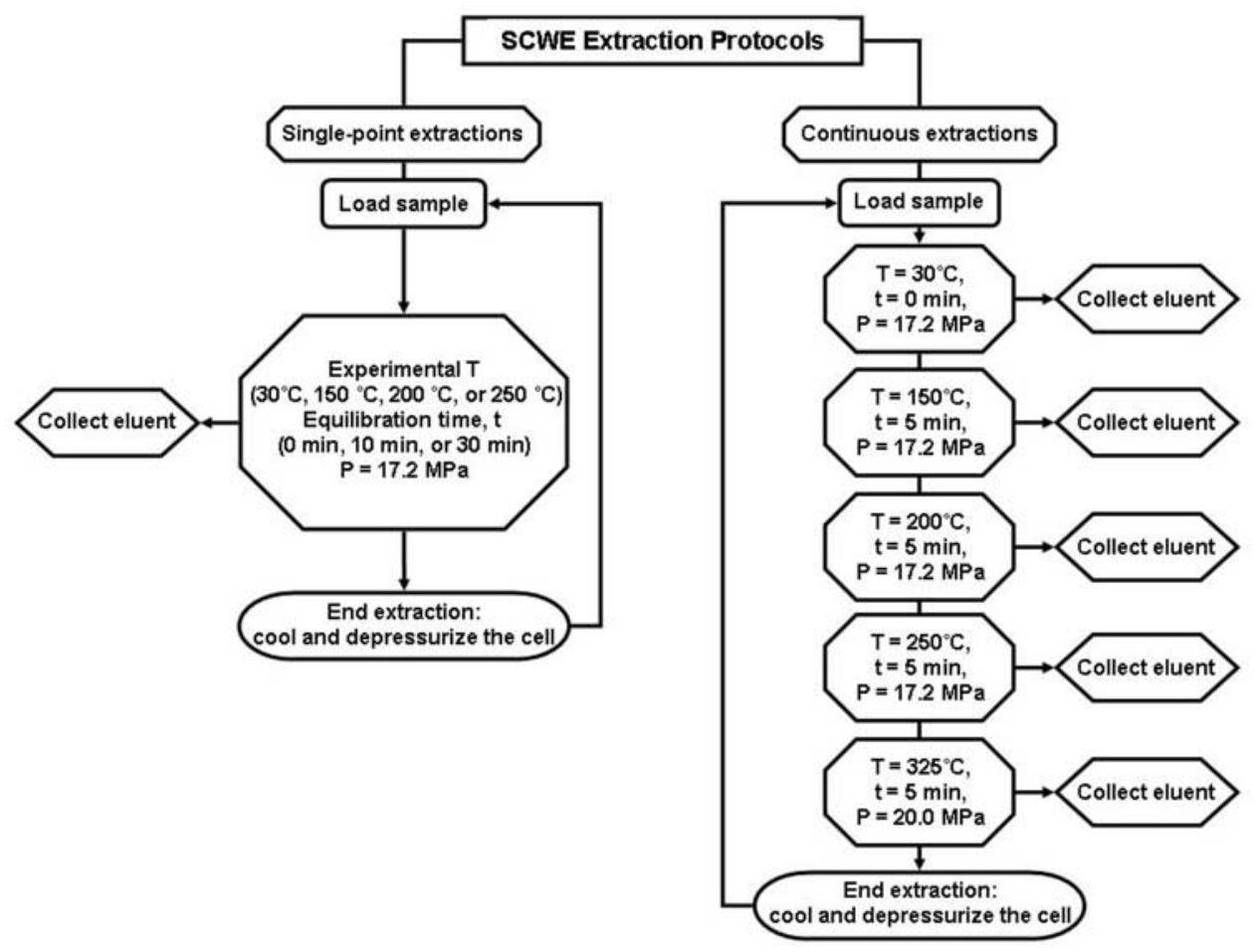

Figure 3. Operational diagram for the single-point and continuous SCWE extraction protocols. In a typical single-point extraction, the sample is heated under pressure to a single experimental temperature and the eluent is collected after a set equilibration time. In a continuous extraction, the sample is heated to several sequential experimental temperatures. The 6-ml eluent fractions are collected after set equilibration times.

pressure was generally maintained at $17.2 \mathrm{MPa}$, but was raised to $20 \mathrm{MPa}$ for the equilibration step at $325{ }^{\circ} \mathrm{C}$.

\subsection{SCWE Operational Sequence}

[11] The basic SCWE operational sequence for both types of extraction protocols consisted of the following: (1) at $30{ }^{\circ} \mathrm{C}, 18-\mathrm{M} \Omega$ water was slowly pressurized to $17.2 \mathrm{MPa}$ as it passed through the sample cell and the flow restrictor; (2) as the supply and eluent valves were closed, the water and sample cell were sealed under pressure and checked for water leaks; (3) the water and the sample cell were then heated to the experimental temperature at $17.2 \mathrm{MPa}$ (the system was pressurized to $20 \mathrm{MPa}$ when the temperature was raised to $325{ }^{\circ} \mathrm{C}$ to maintain water in the liquid state); (4) as the sample reached a set experimental temperature, the supply valve was opened and the soil sample was allowed to interact with subcritical water for a set equilibration time; (5) at the end of the equilibration time, the eluent valve was opened and the amino-acid-containing extract was collected in a crimped-top vial.

[12] Each extraction experiment was repeated a minimum of three times to ensure reproducibility of the extraction results. The sample cells were cleaned in water, then sonicated at $60{ }^{\circ} \mathrm{C}$, and dried in an oven at $130{ }^{\circ} \mathrm{C}$ for at least two hours before each use. To minimize possible crosscontamination in single-point extraction studies, each extraction used the same sample cell when the temperature and equilibration time were the same. For continuous extractions, the same sample cell was used in all studies, since experimental conditions did not vary. Since extraction experiments depend on a number of experimental variables (e.g., temperature, pressure, flow rates), the sequence in which single-point extraction conditions were studied was designed to minimize the interdependence of the individual extraction experiments. For instance, $200{ }^{\circ} \mathrm{C}$ and 10 -min extractions were performed on different dates and not in sequence with other $200{ }^{\circ} \mathrm{C}$ or 10 -min extractions. Since the valves, filters, and flow restrictors can potentially trap amino acids after each extraction, $30 \mathrm{ml}$ of $17.2 \mathrm{MPa}$ water was passed through the SCWE instrument after each extraction to reduce cross-contamination. The water blanks were collected, after passing water through the instrument with no sample cell in place, before each experiment. All of the results presented in this paper are blank-corrected.

\subsection{Sample Preparation and HPLC Analysis}

[13] Soil samples were collected from site 44 on Yungay 1122 hill in the Chilean Atacama Desert (S 24 $4^{\circ} 03.651^{\prime}$; W $69^{\circ} 52.102^{\prime}$ ). The samples designated AT44A2_08 were obtained at a depth of approximately $1.5 \mathrm{~cm}$ and stored in sterile plastic bags. The selection of the sampling sites, the procedure for sampling, and the site labeling protocol are described in detail by Skelley et al. [2007]. After collection and return to the laboratory, the soil samples were homogenized in a clean room environment and stored in sterile glass containers. The $1.0-\mathrm{g}$ soil aliquots for the SCWE experiments were obtained from the same glass container.

[14] The SCWE amino acid extracts were frozen and dried with a MicroModulyo-115 freeze-drier (Thermo Electron Corp., Marietta, Ohio). The dried samples were reconstituted 
Table 1. Summary of the Extraction Results for Amino Acids ${ }^{\mathrm{a}}$

\begin{tabular}{|c|c|c|c|c|c|c|c|}
\hline$T$ & $t$ & Aspartic Acid & Glutamic Acid & Serine & Glycine & Alanine & Valine \\
\hline \multicolumn{8}{|c|}{ Single-Point Protocol Extractions Data } \\
\hline 30 & 10 & $\begin{array}{l}\text { Below detection } \\
\text { level }\end{array}$ & $\begin{array}{l}\text { Below detection } \\
\text { level }\end{array}$ & $\begin{array}{l}\text { Below detection } \\
\text { level }\end{array}$ & $\begin{array}{l}\text { Below detection } \\
\text { level }\end{array}$ & $\begin{array}{c}\text { Below detection } \\
\text { level }\end{array}$ & $\begin{array}{l}\text { Below detection } \\
\text { level }\end{array}$ \\
\hline 150 & 0 & $\begin{array}{l}\text { Below detection } \\
\text { level }\end{array}$ & $16 \pm 6$ & $2 \pm 1$ & $3 \pm 1$ & $\begin{array}{l}\text { Below detection } \\
\text { level }\end{array}$ & $\begin{array}{l}\text { Below detection } \\
\text { level }\end{array}$ \\
\hline 150 & 10 & $4 \pm 1$ & $20 \pm 3$ & $3 \pm 1$ & $8 \pm 5$ & $\sim 1 \pm 0.5$ & $2 \pm 1$ \\
\hline 150 & 30 & $\begin{array}{l}\text { Below detection } \\
\text { level }\end{array}$ & $6 \pm 3$ & Below detection level & $9 \pm 3$ & $2 \pm 1$ & $\begin{array}{l}\text { Below detection } \\
\text { level }\end{array}$ \\
\hline 200 & 0 & $\begin{array}{l}\text { Below detection } \\
\text { level }\end{array}$ & $13 \pm 3$ & $3 \pm 1$ & $5 \pm 1$ & $4 \pm 1$ & $\sim 1 \pm 0.2$ \\
\hline 200 & 10 & $33 \pm 13$ & $6 \pm 1$ & $5 \pm 2$ & $32 \pm 11$ & $10 \pm 3$ & $3 \pm 1$ \\
\hline 200 & 30 & $28 \pm 3$ & $4 \pm 3$ & Below detection level & $41 \pm 9$ & $34 \pm 3$ & $11 \pm 1$ \\
\hline 250 & 0 & $\begin{array}{l}\text { Below detection } \\
\text { level }\end{array}$ & $9 \pm 4$ & $\sim 1 \pm 0.5$ & $30 \pm 11$ & $12 \pm 2$ & $2 \pm 0$ \\
\hline 250 & 10 & $8 \pm 1$ & $4 \pm 0.4$ & $4 \pm 0.3$ & $69 \pm 6$ & $60 \pm 5$ & $22 \pm 2$ \\
\hline 250 & 30 & $\begin{array}{l}\text { Below detection } \\
\text { level }\end{array}$ & $4 \pm 1$ & $\sim 1 \pm 0.2$ & $44 \pm 9$ & $38 \pm 8$ & $16 \pm 3$ \\
\hline \multicolumn{8}{|c|}{ Continuous Protocol Extraction Data } \\
\hline 30 & 0 & $\begin{array}{l}\text { Below detection } \\
\text { level }\end{array}$ & $2 \pm 1$ & $\begin{array}{l}\text { Below detection } \\
\text { level }\end{array}$ & $\begin{array}{l}\text { Below detection } \\
\text { level }\end{array}$ & $\begin{array}{l}\text { Below detection } \\
\text { level }\end{array}$ & $\begin{array}{l}\text { Below detection } \\
\text { level }\end{array}$ \\
\hline 150 & 5 & $\begin{array}{l}\text { Below detection } \\
\text { level }\end{array}$ & $10 \pm 2$ & $\sim 1 \pm 0.5$ & $1 \pm 0.8$ & $\sim 1 \pm 0$ & $\sim 1 \pm 0$ \\
\hline 200 & 5 & $\begin{array}{l}\text { Below detection } \\
\text { level }\end{array}$ & $\begin{array}{l}\text { Below detection } \\
\text { level }\end{array}$ & $\begin{array}{l}\text { Below detection } \\
\text { level }\end{array}$ & $3 \pm 1$ & $4 \pm 1$ & $2 \pm 1$ \\
\hline 250 & 5 & $\begin{array}{l}\text { Below detection } \\
\text { level }\end{array}$ & $5 \pm 1$ & $\begin{array}{l}\text { Below detection } \\
\text { level }\end{array}$ & $11 \pm 3$ & $25 \pm 9$ & $6 \pm 2$ \\
\hline 325 & 5 & $\begin{array}{l}\text { Below detection } \\
\text { level }\end{array}$ & $\begin{array}{l}\text { Below detection } \\
\text { level }\end{array}$ & $\begin{array}{l}\text { Below detection } \\
\text { level }\end{array}$ & $\begin{array}{l}\text { Below detection } \\
\text { level }\end{array}$ & $\begin{array}{l}\text { Below detection } \\
\text { level }\end{array}$ & $\begin{array}{l}\text { Below detection } \\
\text { level }\end{array}$ \\
\hline \multicolumn{8}{|c|}{ HCl Vapor-Phase Hydrolysis Data } \\
\hline & & $36 \pm 11$ & $118 \pm 42$ & $13 \pm 7$ & $43 \pm 24$ & $126 \pm 50$ & $100 \pm 23$ \\
\hline
\end{tabular}

\footnotetext{
${ }^{a}$ Amino acid concentrations are given in ppb. The extraction values are blank-corrected. The errors are calculated from the standard deviations for
} subcritical water extractions and standard deviation of the mean for the acid hydrolysis samples.

with $1 \mathrm{ml}$ of $18-\mathrm{M} \Omega$ water and desalted using AG50W-X8 cation-exchange resin (BioRad, Hercules, California). Amino acids were eluted from the columns with a $2.0 \mathrm{M}$ ammonium hydroxide solution (Sigma-Aldrich Corp., St. Louis, Missouri) and freeze-dried. The dried samples were derivatized for HPLC with AccQ.Fluor ${ }^{\mathrm{TM}}$ reagent (6-aminoquinolyl-Nhydroxysuccinimidyl carbamate) according to Waters AccQ $\cdot \operatorname{Tag}^{\text {TM }}$ procedure [Cohen and Michaud, 1993]. The AccQ. Fluor ${ }^{\text {TM }}$ reagent reacted rapidly with amino acids yielding ureas (fluorescence $\lambda_{\max }=395 \mathrm{~nm}$ ), which were stable at room temperature for up to one week. The excess labeling reagent reacted rapidly with water yielding 6-aminoquinoline, N-hydroxysuccinimide, and carbon dioxide. The only hydrolysis product that weakly fluoresced at $395 \mathrm{~nm}$ was 6-aminoquinoline, which was resolved chromatographically and did not interfere with the HPLC analyses.

[15] The vapor-phase $\mathrm{HCl}$ acid hydrolyses of 1.0-g soil samples were performed according to a standard procedure [Kvenvold et al., 1970]. The hydrolyzed samples were reconstituted in $1 \mathrm{ml}$ of $18-\mathrm{M} \Omega$ water, desalted and analyzed in the same way as the SCWE amino acid extracts.

[16] The HPLC analyses were performed with a Waters 2696 Separation Module equipped with a Waters 2475 multi-wavelength fluorescence detector and a column heater (Waters Corp., Milford, Massachusetts). Amino acids were separated on Waters AccQ· Tag $^{T M}$ high-efficiency $\mathrm{C}_{18}$ column with the temperature set to $37{ }^{\circ} \mathrm{C}$ for maximum chromatographic resolution. The gradient table for Waters
AccQ. Tag ${ }^{\mathrm{TM}}$ method was used without changes and is outlined in detail in the Waters AccQ. Tag ${ }^{\mathrm{TM}}$ Chemistry Package Instruction Manual (Waters Corp., Milford, Massachusetts). The samples were excited at $250 \mathrm{~nm}$, and the fluorescence signals were collected at $395 \mathrm{~nm}$. HPLC data recording and analyses were performed with MassLynx v.4 software (Waters Corp., Milford, Massachusetts). External standard calibration curves were generated for each amino acid $\left(\mathrm{R}^{2}=\right.$ $0.999 \pm 0.001)$ for the $0.05-1.0 \mathrm{nmol}$ range.

\section{Results}

[17] The summary of the single-point and continuous extraction data and the $\mathrm{HCl}$ vapor-phase hydrolysis results are given in Table 1 . The single-point extractions were performed at $30{ }^{\circ} \mathrm{C}, 150{ }^{\circ} \mathrm{C}, 200{ }^{\circ} \mathrm{C}$, and $250{ }^{\circ} \mathrm{C}$; at a constant pressure of $17.2 \mathrm{MPa}$; and 0 -min, 10-min, and 30-min equilibrations times. In single-point extractions, the optimal equilibration time for most amino acids is 10 minutes. Significant reduction of amino acid concentrations was observed when soil samples were exposed to subcritical water for 30 minutes, with an exception of aliphatic amino acids, which concentrations increase at $200{ }^{\circ} \mathrm{C}$. The concentrations of amino acids are below the detection levels in the extracts collected at 0 -min equilibration time, suggesting that this particular soil sample lacked free, nonbound, amino acids and that this equilibration time was not sufficient to yield detectable amounts of amino 


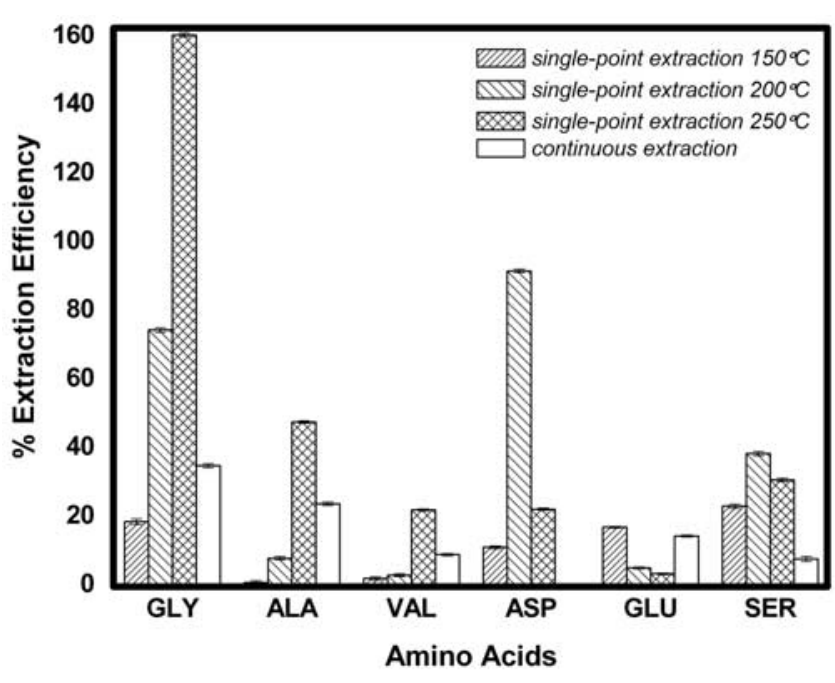

Figure 4. SCWE amino acid extraction efficiency for single-point (with 10-min equilibration time) and continuous protocols. The SCWE extraction efficiency is defined as the ratio of the SCWE extraction data to the $\mathrm{HCl}$ hydrolysis data for each amino acid: (x/y*100\%), where $\mathrm{x}$ and $\mathrm{y}$ are the SCWE extraction and $\mathrm{HCl}$ hydrolysis data, respectively. The error bars $( \pm \delta \mathrm{z})$ are derived from a standard error propagation calculation: $\delta \mathrm{z}=\left[(\delta \mathrm{x} / \mathrm{x})^{2}+(\delta \mathrm{y} /\right.$ $\left.\mathrm{y}^{2}\right]^{1 / 2}$, where $\delta \mathrm{x}, \delta \mathrm{y}$, and $\delta \mathrm{z}$ are the SCWE standard deviation, the $\mathrm{HCl}$ standard deviation of the mean values, and the SCWE efficiency error, respectively.

acids. The concentration of glycine, alanine, and valine was maximized at $200{ }^{\circ} \mathrm{C}$ and $250{ }^{\circ} \mathrm{C}$, while amino acids with polar side chains, such as glutamic acids, were extracted at significantly higher levels at $150{ }^{\circ} \mathrm{C}$, suggesting that the optimal extraction temperature for all amino acids examined in this paper is approximately $200{ }^{\circ} \mathrm{C}$.

[18] In the continuous extraction protocol, the 6-ml eluents were collected at $30{ }^{\circ} \mathrm{C}, 150{ }^{\circ} \mathrm{C}, 200{ }^{\circ} \mathrm{C}, 250{ }^{\circ} \mathrm{C}$, and $325^{\circ} \mathrm{C}$ and $17.2-20.0 \mathrm{MPa}$. A 5-min equilibration time was used for all of the extraction points, with an exception of $30{ }^{\circ} \mathrm{C}$, where 0 -min equilibration period was used. As in the case of single-point extractions, aliphatic amino acids were extracted more efficiently at higher temperatures, e.g., $250{ }^{\circ} \mathrm{C}$, while polar side chain amino acids were collected more effectively at the lower temperature $\left(150^{\circ} \mathrm{C}\right)$. Aspartic acid was not detected using continuous extraction and was only detected in single-point extracts. The overall amount of amino acids extracted using the continuous extraction method was also lower than the single-point extraction yields. In addition, amino acids were not detected from the fractions collected at $325{ }^{\circ} \mathrm{C}$ and $30{ }^{\circ} \mathrm{C}$, with an exception of very small amounts of glutamic acid at $30^{\circ} \mathrm{C}$. The explanation for the absence of a detectable amount of glutamic acid in $200{ }^{\circ} \mathrm{C}$ is not clear at this time, but it is most likely due to the decomposition processes.

\section{Discussion}

[19] The results of the Viking experiments [e.g., Biemann et al., 1976; Biemann, 1979; Biemann and Lavoie, 1979; Oyama et al., 1976, 1977; Levin and Straat, 1977a, 1977b] suggest that significantly more sensitive methods for the detection and analysis of biomarker compounds are needed for in situ characterization of organic compounds in the Martian regolith. In addition, the extraction methods by which biomarker molecules are obtained from their native environments are critical, since they ultimately define the success of the detection and the analysis experiments. In this paper, we have successfully demonstrated the performance of SCWE in extraction of trace amounts of amino acids from Mars-like Atacama Desert soils. Our results are in excellent agreement with previously reported amino acid data for this region [Skelley et al., 2005] and support the observations made from the 2005 Yungay field study, where extracts from the portable SCWE field unit [Amashukeli et al., 2006] were analyzed by a portable microfluidic capillary electrophoresis $(\mu-\mathrm{CE})$ instrument [Skelley et al., 2007]. The slight differences between the laboratory and the field extraction results are likely due to the more optimized laboratory extraction protocols. Since amino acids were not detected in HPLC analysis of single-point $30{ }^{\circ} \mathrm{C}$ extracts, the concentrations of free, nonbound amino acids in our soil sample are rather negligible, making it necessary for the subcritical water to interact with the soil for some minimum equilibration time at elevated temperatures. Our extraction data suggests that the optimal equilibration time for these soil samples is 10 minutes.

[20] Skelley and Mathies [2007] have demonstrated that acid hydrolysis of $E$. coli cells releases approximately $5 \times$ $10^{-16} \mathrm{~mol}$ of valine per cell. With this conversion factor and the observed extracted valine concentrations, the one gram of AT44A2 08 soil contains approximately $10^{5}$ cell equivalents. Skelley et al. [2007] estimated $\sim 10^{6}$ cell $/ \mathrm{g}$ for the same site, but for the soil samples collected at a lower depth. Both estimates are higher than values reported by NavarroGonzales et al. [2003] for the exposed soil samples. Unlike colony forming unit experiments, which depend on the presence of viable cells in soil samples and appropriate culture conditions for the cell growth, the SCWE is capable of extracting amino acids from both viable and nonviable cells. Therefore, the estimates of the number of cell equivalents in the soil sample are expected to be higher when extrapolated from the SCWE experimental results.

[21] We assume in our analysis that the extraction efficiency of the $\mathrm{HCl}$ hydrolysis is effectively $100 \%$. Consequently, the SCWE extraction results are compared to the hydrolysis data to establish the SCWE extraction efficiency. The data in Figure 4 show that the SCWE extraction efficiency for each amino acid is a function of temperature. Glycine, alanine, and valine exhibit the highest single-point extraction efficiencies at $200{ }^{\circ} \mathrm{C}$ and $250{ }^{\circ} \mathrm{C}$, while aspartic acid and serine are more readily extracted at $200{ }^{\circ} \mathrm{C}$, and glutamic acid at $150{ }^{\circ} \mathrm{C}$. Of all the amino acids studied, aspartic acid and glycine are the most stable under singlepoint subcritical extraction conditions $\left(200{ }^{\circ} \mathrm{C}\right.$ and 10 minutes), with extraction efficiencies of $92 \pm 0.5 \%$ and $74 \pm 1 \%$, respectively. With the exception of glycine, the continuous amino acid extraction efficiencies are relatively low. A typical continuous extraction takes approximately $46 \pm 1$ min to complete, while the total optimal single-point extraction time is only $14 \pm 1 \mathrm{~min}$. The prolonged exposure of free amino acids during continuous extraction protocol to subcritical water at elevated temperatures is most likely 


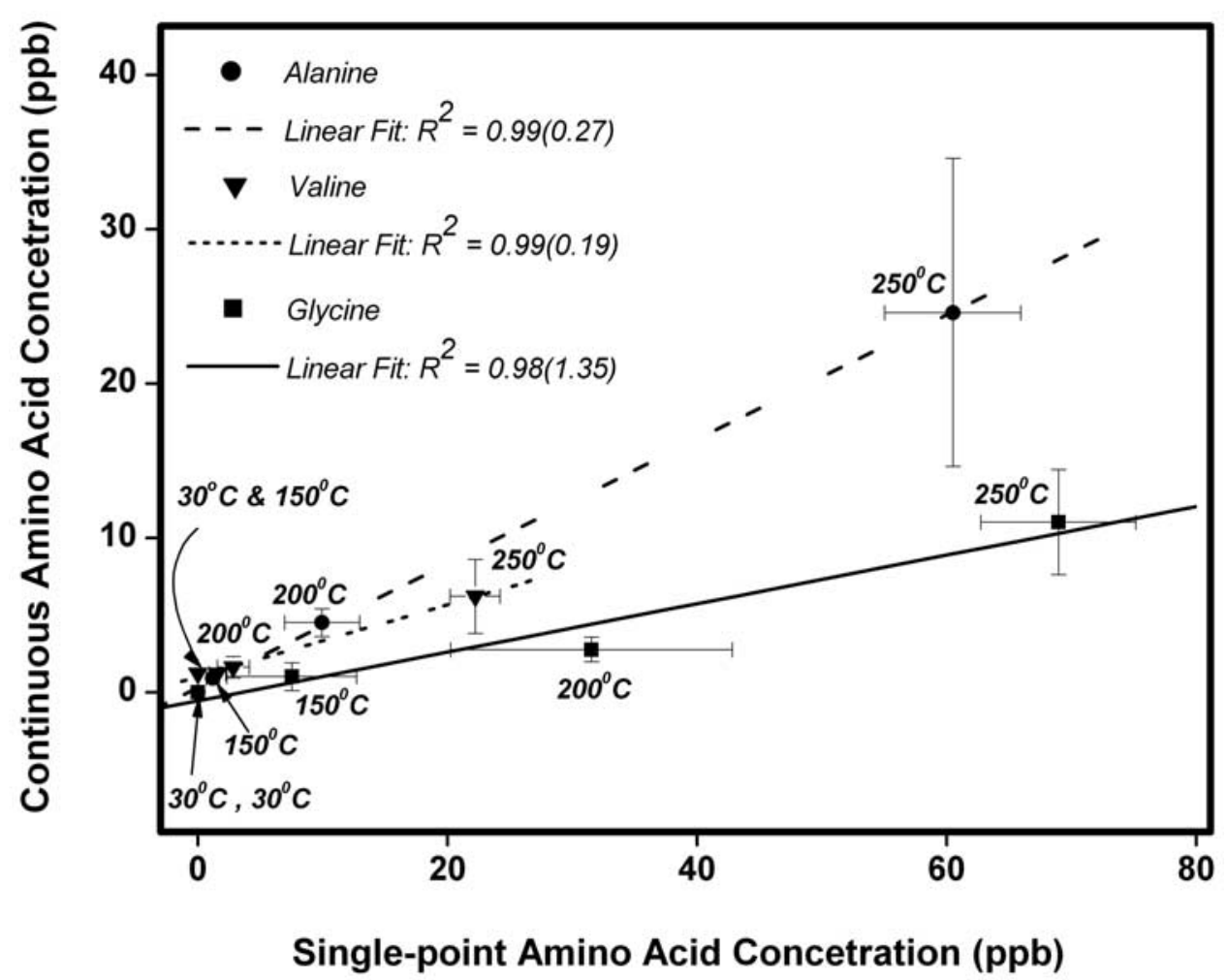

Figure 5. Comparison of single-point and continuous extraction protocols for aliphatic amino acids. The slightly worse linear fit for glycine data is most likely due to the elevated concentration of glycine in $250{ }^{\circ} \mathrm{C}$-extracts. The $\mathrm{x}$-axis and $\mathrm{y}$-axis error bars correspond to the standard deviations for the singlepoint and continuous subcritical water extraction results, respectively.

responsible for the reduction in recovered amino acids due to the decomposition processes.

[22] In Figure 5, the continuous extraction data is plotted as a function of single-point extraction data for aliphatic amino acids collected at different temperatures and 10-min equilibration times. Strong linear correlations between the data sets are observed. Independent of the SCWE protocols used, alanine, valine, and glycine concentrations increase with increasing subcritical water temperature, signifying that the mechanism by which these amino acids are extracted from soil is similar for both extraction protocols. Linear correlations between the extraction data for glutamic acid collected with two different SCWE protocols is very poor, while the linear correlation does not exist for aspartic acid and serine. One possible explanation is that these amino acids decompose more readily under continuous extraction conditions, impeding the direct comparison between two different extraction protocols.

[23] The SCWE performance success ultimately depends on the thermodynamic and kinetic stability of hydrolyzed amino acids and their solubility in subcritical water. In the SCWE, the solubility is directly controlled by adjustments of temperature and pressure. The thermodynamic and kinetic stability of amino acids depends on the rates of the chemical reactions responsible for the liberation of amino acids from the solid matrix and the decomposition reaction rates, all of which are functions of subcritical water temperature, pressure, and equilibration time. In the SCWE studies, the most likely mechanism by which amino acids are released from the solid matrix is peptide bond hydrolysis. Peptide bond hydrolysis reactions are irreversible, first-order rate processes in which rate constants increase exponentially with increasing temperature, as shown by Qian et al. [1993] and Lawrence and Moore [1951] for the case of glycine peptides. It has been reported that the rates of these reactions also increase at high pressures, since activation energies are lower under these high-temperature and high-pressure conditions [Shock, 1992; Qian et al., 1993]. Our extraction data shows that the concentrations of aliphatic amino acids increase with increasing water temperatures at $17.2 \mathrm{MPa}$. More work, focusing on the measurements of the reaction rates during subcritical water extractions from sulfate-rich soils of Atacama Desert, is under way.

[24] Since hydrolyzed amino acids may thermally decompose in subcritical water, the SCWE extraction efficiency will depend on the decomposition reaction rates of free amino acids. Some of the likely mechanisms by which amino acids decompose are through decarboxylation and de-amination reactions. The latter reaction is probably less significant since it requires presence of $\mathrm{H}_{2}$ gas, which is most likely present in trace amounts. Decarboxylation, on the other hand, is considered the dominant pathway of amino acid decomposition in aqueous solutions [Vallentyne, $1964]$ and is most likely responsible for the degradation of extracted amino acids in our SCWE experiments. The mechanisms of decarboxylation reactions are complex; however a direct decarboxylation pathway is possible [Bach and Canepa, 1996; Phillips and Lee, 2001; Sicinska et al., 
2001]. In general, the rates of decarboxylation reactions depend on the type of the side chains and the position of functional groups with respect to $\alpha$-carbon [e.g., $\mathrm{Li}$ and Brill, 2003a, 2003c]. The rate constants of decarboxylation reactions increase exponentially with increasing temperature [Qian et al., 1993]. It is likely, therefore, that fast decarboxylation rates are responsible for the absence of amino acids in $325{ }^{\circ} \mathrm{C}$ extraction fractions collected during continuous SCWE protocol.

[25] The substitution of an $\alpha$-hydrogen in glycine by alkyl groups is reported to slow down the hydrolysis reactions [Synge, 1945]. This is one of the likely explanations for the observed high SCWE extraction efficiency of glycine in comparison to other aliphatic amino acids. Since hydrolysis rates increase with temperature and pressure, the high concentrations of glycine, alanine, and valine in singlepoint extractions at $250{ }^{\circ} \mathrm{C}$ and $17.2 \mathrm{MPa}$ are most likely due to the faster hydrolysis reaction rates. The decomposition reactions of glycine, alanine, and valine at $200{ }^{\circ} \mathrm{C}$ and $250{ }^{\circ} \mathrm{C}$ and 17.2 $\mathrm{MPa}$ are significant only at a longer (30 min) equilibration time. The decarboxylation reactions of aliphatic amino acids are well-studied and, according to Li and Brill [2003b, 2003c], the rates follow this order: glycine $>$ valine $>$ alanine. Our extraction efficiency data suggests that the hydrolysis reaction rates, which are in competition with decarboxylation reactions, are faster at $250{ }^{\circ} \mathrm{C}$ and 17.2 MPa for these aliphatic amino acids.

[26] Glutamic acid has the highest concentration of all amino acids in single-point extractions at $150{ }^{\circ} \mathrm{C}$ and 17.2 $\mathrm{MPa}$, suggesting, that, in addition to being highly soluble in the subcritical water solvent, the decarboxylation rates are slow under these subcritical water conditions. The stability of glutamic acid decreases significantly with increasing temperature, suggesting that the decomposition rates are higher at $200{ }^{\circ} \mathrm{C}$ and $250{ }^{\circ} \mathrm{C}$ than the competing hydrolysis rates. The most likely decomposition mechanism involves a fast equilibrium intramolecular dehydration reaction of glutamic acid. The product of that reaction is pyroglutamic acid, which, in turn, undergoes a decarboxylation reaction yielding pyrrolidine carboxylic acid [Povoledo and Vallentyne, 1964]. Pyroglutamic acid has a high thermal stability, and the fast equilibrium between glutamic acid and pyroglutamic acid favors the product [Li and Brill, 2003b, and references therein]. All these factors reduce glutamic acid SCWE extraction efficiency.

[27] The optimal single-point extraction temperature at 17.2 $\mathrm{MPa}$ for aspartic acid and serine is $200{ }^{\circ} \mathrm{C}$. Their concentrations decrease at longer equilibration times (30 min) and $250{ }^{\circ} \mathrm{C}$, indicating that the decomposition pathway is more significant under these subcritical water conditions. In addition to decarboxylation, aspartic acid is reported to undergo de-amination reactions more readily [Sohn and Ho, 1995] than the other amino acids studied here. The extraction efficiency of serine can also be reduced by dehydration and aldol cleavage decomposition reactions [e.g., Bada et al., 1978]. One of the products of the aldol cleavage of serine is glycine. It is likely that the serine decomposition reaction contributes to the observed high concentrations of glycine in $250{ }^{\circ} \mathrm{C}$-extracts, where the concentration of glycine is significantly higher than the $\mathrm{HCl}$ vapor hydrolysis values.
[28] In addition to the decomposition reaction of hydrolyzed amino acids, other chemical processes might reduce the amino acid extraction yields. Among them are the reversible, fast peptide cyclization reactions [Steinberg and Bada, 1981, 1983; Mitter and Kriausakul, 1984] and direct decomposition of the peptides via decarboxylation or de-amination. In the latter case, the rates are significantly slower than those of the hydrolysis reactions [Qian et al., 1993]. Although these competing reactions are insignificant in comparison to the hydrolysis and hydrolyzed amino acid decompositions, they still contribute to the overall decrease in amino acid extraction efficiency. In addition, the solid matrix itself may have a reducing potential or catalytic property that affects the rates of the decomposition reactions and the overall yield of the extraction experiments.

[29] Ultimately, the question of the presence of salts in the subcritical water extracts must be considered. Skelley et al. [2007] have demonstrated in the field studies with the portable SCWE, that extracts were successfully analyzed by $\mu$-CE instrument, although the salts were present in the eluents. Salts, however, might act as chelating agents, which can bind to the target molecules, therefore reducing the concentration of biomarkers available for analysis. The conductivity measurements of the soil extracts suggest that salts are more efficiently extracted at lower temperatures, due to the higher dielectric constant of water (X. Amashukeli, manuscript in preparation, 2007). It is, therefore, possible to rid the sample of the majority of salts through low-temperature extraction without compromising amino acid extraction efficiencies, since bound amino acids are not readily extracted under these conditions and their loss will be minimal. In this study, we have used cation exchange columns to desalt our samples. This desalting method, however, is labor intensive and time consuming. Another approach would be to combine the subcritical water extraction with sublimation techniques, where the extracted samples are freeze-dried and the amino acids are sublimed. Currently, we are in the process of integrating the SCWE with the Mars Organic Detector (MOD) instrument [Kminek et al., 2000] that will perform extractions and sublimations in a series of operations as we develop the integrated in situ Urey instrument.

\section{Summary}

[30] In summary, the results presented in this paper demonstrate that the SCWE extraction methods are successful at extracting trace amounts of amino acids from Atacama Desert soils collected from the Mars-analog Yungay region. The number of cell equivalents in one gram of soil is estimated to be slightly higher than previously reported for the exposed soil samples owing to the ability of the SCWE to extract amino acids from both viable and nonviable cells. The single-point extraction protocol executed at $200{ }^{\circ} \mathrm{C}, 17.2 \mathrm{MPa}$, and 10-min equilibration time yielded the best overall extraction results for this Atacama Desert sample. These optimized extraction protocols developed in the laboratory are enabling further engineering improvements and optimization of the portable SCWE units as well as development of extraction protocols for other biomarker molecules. These optimized protocols together with new instrumental developments will be used in future field 
studies focused on extraction and detection of trace amounts of biomarkers in Mars-like regions on Earth.

[31] Acknowledgments. We would like to thank Peter A. Willis, Alison M. Skelley, and Andrew Aubrey for providing sample AT44A2 08 used in this study. We thank Justine Owen and Ronald Amundson for providing the GPS coordinates of Yungay 1122 hill and suggesting its appropriateness for these extensive studies. The research described in this paper was carried out at the Jet Propulsion Laboratory, California Institute of Technology, under contract with National Aeronautics and Space Administration. The research was supported through Jet Propulsion Laboratory Research and Technology Development funds.

\section{References}

Amashukeli, X., S. B. Patrick, J. P. Kirby, C. C. Pelletier, D. B. Bickler, P. A. Willis, C. Bryson, and F. J. Grunthaner (2006), Subcritical water extraction for planetary exploration, New Technol. Rep. 44144, Jet Propul. Lab., Calif. Inst. of Technol., Pasadena.

Bach, R. D., and C. Canepa (1996), Electronic factors influencing the decarboxylation of beta-keto acids. A model enzyme study, J. Org. Chem., 61(18), 6346-6353.

Bada, J. L., M. Y. Shou, E. H. Man, and R. A. Schroeder (1978), Decomposition of hydroxy amino acids in faramineferal tests - kinetics, mechanism and geochronological implications, Earth Planet. Sci. Lett., 41(1), $67-76$.

Bada, J. L., et al. (2005), New strategies to detect life on Mars, Astron. Geophys., 46, 26-27.

Bernhardt, G., H. D. Ludemann, R. Jaenicke, H. Konig, and K. O. Stetter (1984), Biomolecules are unstable under "black smoker" conditions, Naturwiss, 71, 583-586.

Biemann, K. (1979), Implications and limitations of the findings of the Viking organic analysis experiment, J. Molecular Evolution, 14(1-3), $65-70$.

Biemann, K., and J. M. Lavoie (1979), Some final conclusions and supporting experiments related to the search for organic compounds of the surface of Mars, J. Geophys. Res., 84, 8385-8390.

Biemann, K., et al. (1976), Search for organic and volatile inorganic compounds in two surface samples from Chryse-Planitia region of Mars, Science, 194(4260), 72-76.

Cameron, R. E., and G. B. Blank (1965), Soil studies - desert microflora. X. Soil properties of samples from Chile Atacama Desert, JPL Space Programs Summary, 37-35(IV), 214-222.

Cohen, S. A., and D. P. Michaud (1993), Synthesis of a fluorescent derivatizing reagent, 6 -aminoquinolyl- $N$-hydroxysuccinimidyl carbamate, and its application for the analysis of hydrolysate amino acids via highperformance liquid chromatography, Anal. Biochem., 211, 279-287.

Cronin, J. R., S. Pizarello, and D. P. Cruikshank (1988), Organic matter in carbonaceous chondrites, planetary satellites, asteroids, and comets, in Meteorites and the Early Solar Systems., edited by J. F. Kerridge and M. S. Matthews, pp. 819-857, Univ. of Ariz. Press, Tucson.

Ericksen, G. E. (1983a), The Chilean nitrate deposits, Am. Sci., 71, 366374.

Ericksen, G. E. (1983b), Geology and origin of the Chilean nitrate deposits, Geol. Soc. Am. Spec. Pap., 1188, 37.

Fernandez, D. P., A. R. H. Goodwin, E. W. Lemmon, J. M. H. L. Sengers, and R. C. Williams (1997), A formulation for the static permittivity of water and steam at temperatures from $238 \mathrm{~K}$ to $873 \mathrm{~K}$ at pressures up to $1200 \mathrm{MPa}$, including derivatives and Debye-Hückel coefficients, J. Phys Chem. Ref. Data, 26(4), 1125-1166.

Hartonen, K., K. Inkala, M. Kangas, and M. L. Riekkola (1997), Extraction of polychlorinated biphenyls with water under subcritical conditions, J. Chromatogr. A, 785(1-2), 219-226.

Hawthorne, S. B., Y. Yang, and D. J. Miller (1994), Extraction of organic pollutants from environmental solids with subcritical and supercritical water, Anal. Chem., 66(18), 2912-2920.

Hawthorne, S. B., C. B. Grabanski, E. Martin, and D. J. Miller (2000), Comparisons of soxhlet extraction, pressurized liquid extraction, supercritical fluid extraction and subcritical water extraction for environmental solids: recovery, selectivity and effects on sample matrix, J. Chromatogr. A, 892(1-2), 421-433.

Ibanez, E., A. Kubatova, F. J. Senorans, S. Cavero, G. Reglero, and S. B. Hawthorne (2003), Subcritical water extraction of antioxidant compounds from rosemary plants, J. Agric. Food Chem., 51(2), 375-382.

Keil, R. G., and D. L. Kirchman (1991), Dissolved combined amino-acids in marine waters as determined by vapor phase hydrolysis method, Mar Chem., 33, 243-259.

Klein, H. P. (1978), The Viking biological experiments on Mars, Icarus, 34, 666-674.
Klein, H. P. (1979), The Viking mission and the search for life on Mars, Rev. Geophys., 17, 1655-1662.

Kminek, G., J. L. Bada, O. Botta, D. P. Glavin, and F. J. Grunthaner (2000), MOD: an organic detector for the future robotic exploration of Mars, Planet. Space Sci., 48(11), 1087-1091.

Kvenvold, K. A., E. Peterson, and F. S. Brown (1970), Racemization of amino acids in sediments from Saanich-Inlet, British Columbia, Science, 169(3950), 1079-1970.

Lagadec, A. J. M., D. J. Miller, A. V. Lilke, and S. B. Hawthorne (2000), Pilot-scale subcritical water remediation of polycyclic aromatic hydrocarbon- and pesticide-contaminated soil, Environ. Sci. Technol., 34(8), $1542-1548$.

Lawrence, L., and W. J. Moore (1951), Kinetics of the hydrolysis of simple glycine peptides, J. Am. Chem. Soc, 73(8), 3973-3977.

Lester, E. D., M. Satomi, and A. Ponce (2007), Microflora of extreme arid Atacama Desert soils, Soil Biol. Biochem., 39, 704-708.

Levin, G. V., and P. A. Straat (1977a), Recent results from Viking labeled release experiment on Mars, Eos Trans. AGU, 58(8), 829.

Levin, G. V., and P. A. Straat (1977b), Life on Mars - Viking labeled release experiment, Biosystems, $9(2-3), 165-174$

Li, J., and T. B. Brill (2003a), Spectroscopy of hydrothermal reactions 23 : The effect of $\mathrm{OH}$ substitution on the rates and mechanisms of decarboxylation of bezoic acid, J. Phys. Chem. A, 107(15), 2667-2673.

Li, J., and T. B. Brill (2003b), Spectroscopy of hydrothermal reactions 25 : Kinetics of the decarboxylation of protein amino acids and the effect of side chains on hydrothermal stability, J. Phys. Chem. A, 107(31), 59875992.

Li, J., and T. B. Brill (2003c), Spectroscopy of hydrothermal reactions 26: Kinetics of decarboxylation of aliphatic amino acids and comparison with rates of racemization, Int. J. Chem. Kinet., 35(11), 602-610.

McKay, C. P., E. I. Friedmann, B. Gomez-Silva, L. Cáceres-Villanueva, D. T. Andersen, and R. Landheim (2003), Temperature and moisture conditions for like in the extreme arid region of the Atacama Desert: four years of observation including El Nino of 1997-1998, Astrobiology, 3, $393-406$.

Miller, S. L. (1953), The production of amino acids under possible primitive Earth conditions, Science, 117(3046), 528-529.

Miller, S. L., and J. L. Bada (1988), Submarine hot springs and the origin of life, Nature, 334, 609-611.

Mitter, R. M., and N. Kriausakul (1984), Comparison of rates and degrees of isoleucine epimerization in dipeptides and tripeptides, Org. Geochem. 7, $91-98$

Navarro-Gonzales, R., et al. (2003), Mars-like soils in the Atacama Desert, Chile, and the dry limit of microbial life, Science, 302(5647), 1018-1021.

Ong, E. S., J. S. H. Cheong, and D. Goh (2006), Pressurized hot water extraction of bioactive or marker compounds in botanicals and medicinal plant materials, J. Chromatogr. A, 1112(1-2), 92-102.

Oyama, V. I., B. J. Berdahl, G. C. Carle, M. E. Lehwalt, and H. S. Ginoza (1976), Search for life on Mars - Viking 1976 gas changes as indicators of biological activity, Origins of Life and Evolution of the Biosphere, $7(3), 313-333$

Oyama, V. I., B. J. Berdahl, and G. C. Carle (1977), Preliminary findings of Viking gas-exchange experiment and a model for Martian surface chemistry, Nature, 265(5590), 110-114

Phillips, L. M., and J. K. Lee (2001), Theoretical studies of mechanisms and kinetic isotope effects on the decarboxylation of orotic acid and derivatives, J. Am. Chem. Soc., 123(48), 12,067-12,073.

Pizarello, S., and J. R. Cronin (2000), Non-racemic amino acids in the Murray and Murchison meteorites, Geochim. Cosmochim. Acta, 64(2), 329-338.

Povoledo, D., and J. R. Vallentyne (1964), Thermal kinetics of the glutamic acid pyroglutamic acid system in water, Geochem. Cosmochim. Acta, 28, 731-734.

Qian, Y. R., M. H. Engel, S. A. Macko, S. Carpenter, and J. W. Deming (1993), Kinetics of peptide hydrolysis and amino-acid decomposition and high-temperature, Geochim. Cosmochim. Acta, 57(14), 3281-3293.

Quinn, R. C., A. P. Zent, F. J. Grunthaner, P. Ehrenfreund, C. L. Taylor, and J. R. C. Garry (2005), Detection and characterization of oxidizing acids in the Atacama Desert using Mars Oxidation Instrument, Planet. Space Sci., 53, 1376-1388.

Shock, E. L. (1992), Stability of peptides in high-temperature aqueous solutions, Geochim. Cosmochim. Acta, 56, 3481-3491.

Sicinska, D., D. G. Truhlar, and P. Paneth (2001), Solvent-dependent transition states for decarboxylations, J. Am. Chem. Soc., 123(31), 76837686.

Skelley, A. M., and R. A. Mathies (2007), Real-time analysis of glucosamine and its mutoratation by microchip capillary electrophoresis, $J$. Chromatogr. A, in press

Skelley, A. M., J. R. Scherer, A. D. Aubrey, W. H. Grover, R. H. C. Ivester, P. Ehrenfreund, F. J. Grunthaner, J. L. Bada, and R. A. Mathies (2005) 
Development and evaluation of a microdevice fro amino acid biomarker detection and analysis on Mars, Proc. Natl. Acad. Sci., 102(4), $1041-$ 1046.

Skelley, A. M., A. D. Aubrey, P. A. Willis, X. Amashukeli, P. Ehrenfreund, J. L. Bada, F. J. Grunthaner, and R. A. Mathies (2007), Organic amine biomarker detection in the dry Yungay region of the Atacama Desert with the Urey instrument, J. Geophys. Res., G04S11, doi:10.1029/ 2006JG000329.

Sohn, M., and C.-T. Ho (1995), Ammonia generations during thermal degradation of amino acids, J. Agric. Food Chem., 43(12), 3001-3003.

Squyres, S. W., et al. (2004), The Opportunity Rover's Athena science investigation at Meridiani Planum, Mars, Science, 306(5702), 1698 1703.

Steinberg, S. M., and J. L. Bada (1981), Diketopiperazine formation during investigations of amino acid racemization in dipeptides, Science, 213 , $544-545$.

Steinberg, S. M., and J. L. Bada (1983), Peptide decomposition in the neutral $\mathrm{pH}$ region via formation of diketopiperazines, J. Org. Chem., $48,2295-2298$
Synge, R. L. M. (1945), The Kinetics of low temperature acid hydrolysis of gramicidin and some related dipeptides, Biochem. J., 39(4), 351-355.

Tsugita, A., T. Uchida, H. W. Mewes, and T. Ataka (1987), A rapid vaporphase acid (hydrochloric acid and trifluoroacetic acid) hydrolysis of peptide and protein, J. Biochem. (Tokyo), 102, 1593-1597.

Vallentyne, J. R. (1964), Biogeochemistry of organic matter: II. Thermal reaction kinetics and transformation products of amino compounds, Geochim. Cosmochim. Acta, 28, 157-188.

White, R. H. (1984), Hydrolytic stability of biomolecules at high temperatures and its implication for life at $250^{\circ} \mathrm{C}$, Nature, $310,430-432$

Wolfarth, C. (1991), Static dielectric constants of pure liquids and binary liquid mixtures, in Landolt-Börnstein, Numerical Data and Functional Relationships in Science and Technology, New Series, Group IV, Macroscopic and Technical Properties of Matter, vol. 6, edited by O. Madelung, Springer, Berlin.

X. Amashukeli, F. J. Grunthaner, J. P. Kirby, and C. C. Pelletier, Jet Propulsion Laboratory, MS 302-231, 4800 Oak Grove Drive, Pasadena, CA 91109, USA. (frank.j.grunthaner@jpl.nasa.gov) 